\title{
Profiles and changes in stimulant use in Belgium in the period of
}

\section{1-2015}

\author{
Frederic Been ${ }^{1}$, Foon Yin Lai ${ }^{1}$, Juliet Kinyua, Adrian Covaci, Alexander L.N. van Nuijs*
}

Toxicological Center, Department of Pharmaceutical Sciences, University of Antwerp (UA), Universiteitsplein 1, 2610 Antwerp, Belgium

\author{
1 - joint first author \\ * - corresponding author: \\ Dr. Alexander van Nuijs \\ Toxicological Centre, University of Antwerp \\ Universiteitsplein 1 \\ 2610 Wilrijk, Belgium \\ e-mail: alexander.vannuijs@uantwerpen.be \\ tel: +32 (0)32652498 \\ fax: $+32(0) 32652722$
}

(C) 2016. This manuscript version is made available under the Elsevier user license http://www.elsevier.com/open-access/userlicense/1.0/ 


\begin{abstract}
Adapting illicit drug policy strategies requires detailed knowledge on types and amounts of substances consumed by the target population. In this study, we applied wastewater-based epidemiology to detect spatio-temporal changes in the relative amounts of stimulants (amphetamine, methamphetamine, methylenedioxymethamphetamine (MDMA), cocaine) used in seven locations in Belgium over 2011-2015. Clear geographical differences were observed with stimulant users in large cities (Antwerp, Brussels) showing a preference for cocaine, while amphetamine use was most abundant in smaller cities (Geraardsbergen, Koksijde, Lier, Ninove, Ostend). Results obtained across different years revealed that the investigated substances had a stable share in the total amount of stimulants used, suggesting that habits of stimulant use remained constant, although differences in absolute amounts were observed across years. Investigation of the weekly pattern in stimulant use showed an increase in the use of MDMA on the weekends compared to cocaine and amphetamine.
\end{abstract}

Keywords: stimulant use; wastewater-based epidemiology; spatiotemporal changes; cocaine; amphetamine-type stimulants; Belgium 


\section{Introduction}

In order to decrease the negative impact of illicit drugs on human health, social stability and security, there is a need to develop multi-disciplinary, coherent, effective and efficient drug policies, including the implementation of interventions and approaches to reduce both drug demand and supply (EMCDDA, 2013, 2015). In drug demand reduction, a set of measures is applied, focusing on prevention, risk and harm reduction, rehabilitation, and social reintegration. Drug supply reduction consists of actions to disrupt drug-related crimes and law enforcement measures to prevent illicit drug trafficking, distribution, sale, and consumption. However, the specific features of illicit drug markets make it difficult to define and implement optimal drug policies. Illicit drug markets have a highly variable character and can differ significantly in the types and amounts of substances available and used (supply and demand) (Caulkins, 2007). This feature has important implications for policy makers since different substances pose distinct threats to public health, and thus require different strategies with regards to drug supply and demand reduction. Furthermore, differences in illicit drug markets occur on local, regional, national and international scale. This makes the situation very complex, as drug policies should be optimised and readjusted based on both local and global information on illicit drug markets. To tackle the aforementioned issues, there is a need for more and complementary data on drug markets in order to evaluate and refine drug policy strategies on a local and global scale (Muggah, 2015; Caulkins, 2007; Ritter, 2006).

In Belgium, information on the consumption of illicit drugs is obtained through the national health interview survey (HIS) (Gisle, 2014). This questionnaire-based household survey is organised every five years and provides, among other data related to public health, prevalence rates of illicit drug consumption for the adult population (aged 15-64). These prevalence rates are provided for the three regions of Belgium (Wallonia, Flanders, and Brussels) and make a distinction between the age group and the urbanization level (Gisle, 2014). It is clear that the HIS provides useful prevalence data for the regions in Belgium (Wallonia, Flanders and Brussels), but it can neither provide granular data for small communities and cities, nor the relative amounts of illicit drugs used, i.e. which substance is more used in a specific area compared to others.

The properties of wastewater-based epidemiology (WBE) are fit for the purpose of delivering this information as it can provide objective and timely data on the use of multiple illicit drugs in communities of variable size, thus giving an indication about the profile of illicit drug use in the targeted area (Castiglioni et al., 2014). Depending on the area covered by the wastewater collection schemes, information on the typology and amounts used can be obtained at different geographical scales (local, regional, national and international). Furthermore, WBE can provide data in different time resolutions in order to evaluate drug policy interventions and measures: on a short 
term by applying consecutive daily sampling schemes and on a long term through sampling campaigns spanning across multiple years.

This study aims to evaluate the status and profile of the stimulant consumption in Belgium in terms of geographical and temporal differences. To achieve this aim, wastewater sampling campaigns were organised in eight wastewater treatment plants (WWTPs) in Belgium in the period of 2011-2015 and analysed for biomarkers of cocaine, amphetamine (AMP), methylenedioxymethamphetamine (MDMA), and methamphetamine (METH). These were used to characterise and evaluate trends and changes in stimulant use in Belgium.

\section{Materials and methods}

\section{Reagents and chemicals}

The cocaine metabolite benzoylecgonine (BE), amphetamine-like stimulants (AMP, METH, $M D M A)$, and their deuterated analogues $\left(B E-D_{3}, A M P-D_{8}, M E T H-D_{8}, M D M A-D_{5}\right)$ used as internal standards (purity $>98 \%$ ), were purchased from Cerilliant (Round Rock, TX, USA) at concentrations of $1 \mathrm{mg} / \mathrm{mL}$ or $100 \mu \mathrm{g} / \mathrm{mL}$ in methanol $(\mathrm{MeOH})$ or acetonitrile (AcN). Working mixtures at concentrations ranging between 0.05 and $10 \mu \mathrm{g} / \mathrm{mL}$ were prepared in $\mathrm{MeOH}$. LC-grade AcN and $\mathrm{MeOH}$, analytical grade hydrochloric acid $(\mathrm{HCl})$, ammonium hydroxide $\left(\mathrm{NH}_{4} \mathrm{OH}\right)$ and ammonium acetate were purchased from Merck (Darmstadt, Germany). Milli-Q water was obtained by purifying demineralised water in a Milli-Q system (Millipore, Bedford, MA, USA). Oasis MCX (60 mg, $3 \mathrm{cc}$ ) solid-phase extraction (SPE) cartridges were acquired from Waters (New Bedford, MA, USA) and a Supelco Visiprep ${ }^{\text {TM }}$ SPE Vacuum Manifold with 12 ports and a self-cleaning vacuum system ${ }^{\text {TM }}$ Welch 2023 was used for executing the SPE procedure. Final extracts were filtered using $0.45 \mu \mathrm{m}$ centrifugal filters containing modified nylon, acquired from VWR (Leuven, Belgium).

\section{Sampling}

Eight Belgian WWTPs were targeted to collect influent wastewater samples (24-h composite). All WWTPs together cover approximately 1.6 million inhabitants, equivalent to $14 \%$ of the total Belgian population. The sampling locations were chosen in order to include areas with different demographic and urban characteristics (e.g. number of inhabitants, urbanised or rural areas) to generate a representative picture of stimulant use and to evaluate spatial differences. Table 1 and Figure 1 give more details on the targeted sampling locations and the performed sampling schemes. Population data was obtained through combining official population statistics (FOD Economie: http://statbel.fgov.be/nl/statistieken/opendata/datasets/census2011/) with the geographical spread of the WWTP catchment areas (obtained from WWTP operators). Per location 
and sampling year, seven consecutive 24-h composite samples were collected using time- or volume-proportional techniques (Ort et al., 2010). A total of 154 wastewater samples was collected over a period of five years (2011-2015) (see Table 1). Samples were immediately frozen after collection and stored at $-20{ }^{\circ} \mathrm{C}$ until analysis. Whilst all precaution were taken to minimise modifications to the samples after collection and during analysis, uncertainties due to the different sampling modes used in the locations considered here cannot be excluded.

\section{Analysis}

The samples were analysed for excretion products of the aforementioned illicit drugs with a validated method based on SPE and liquid chromatography coupled to tandem mass spectrometry (LC-MS/MS) (van Nuijs et al., 2009). Briefly, $50 \mathrm{~mL}$ of influent wastewater was passed through a glass filter to remove solid particles. Then, deuterated internal standards for quantification were added and a SPE clean-up step on Oasis MCX cartridges was applied. The cartridges were conditioned with $\mathrm{MeOH}$, Milli-Q water and Milli-Q water at $\mathrm{pH}$ 2. After drying, the cartridges were eluted with $4 \mathrm{~mL}$ of $\mathrm{MeOH}$ and $4 \mathrm{~mL}$ of $5 \% \mathrm{NH}_{3}$ in $\mathrm{MeOH}$. The eluate was evaporated and redissolved in $100 \mu \mathrm{L} \mathrm{AcN}$ and $100 \mu \mathrm{L}$ AcN/ammonium acetate $5 \mathrm{mM}$ in water $(90 / 10, v / v)$ followed by a second filtering step on a $0.45 \mu \mathrm{m}$ centrifugal filter. Compounds were separated on an Agilent 1200 series LC system with a Phenomenex Luna HILIC column $(150 \times 3 \mathrm{~mm}, 5 \mu \mathrm{m})$ and a mobile phase consisting of (A) ammonium acetate $5 \mathrm{mM}$ in Milli-Q water and (B) $\mathrm{AcN}$, in gradient. The flow rate was $0.4 \mathrm{~mL} / \mathrm{min}$ and the injection volume was $5 \mu \mathrm{L}$. The MS system was an Agilent 6410 triple quadrupole mass spectrometer equipped with an electrospray ionisation interface operating in positive mode. Quantitative analyses were performed in multiple reaction monitoring mode. With each batch of analysis, a seven-point calibration curve together with quality control samples (blank water spiked with known amounts of the analytes) were analysed and care was taken that the accuracy and precision of the calibrators and quality control samples was within $85 \%-115 \%$ and $<15 \%$ relative standard deviation (RSD), respectively (EMA, 2011). Furthermore, successful participation in interlaboratory exercises was performed as external quality control (Castiglioni et al., 2013).

\section{Calculations}

Daily mass loads of stimulants were calculated by multiplying analyte concentrations, measured in the collected 24-h composite samples, by the corresponding daily flow rate. The amount of pure substance initially consumed was back-calculated by multiplying daily mass loads by the inverse of the excretion rate and, if a metabolite was used for the calculations, the ratio between the molecular weights of the parent compound and the metabolite. Finally, to compute the 
number of doses consumed, back-calculated amounts of substance used were divided by the dosage (i.e. average amount of pure substance found in one dose). All parameters used are reported in Table 2. Monte Carlo simulations were used to perform all calculations and to compute the associated uncertainties (Been et al., 2016, 2015; Jones et al., 2014).

For each day that was analysed, the relative proportions of stimulants used were computed as follows:

$$
P_{i}=d_{i} / \sum_{i}^{n} d_{i} * 100 \quad \text { Equation } 1
$$

where $P_{i}$ is the proportion of doses of any stimulant (i.e. cocaine, amphetamine, methamphetamine or MDMA) consumed on day $i$ in the WWTP catchment, $d_{i}$ is the estimated number of doses consumed on day $i$ and $\sum_{i}^{n} d_{i}$ is the total number of doses (all compounds) consumed in the WWTP during day $i$. For Antwerp, results from the samples collected from its two WWTPs (Antwerpen-Zuid and Deurne) were combined to obtain a single value representative for the whole city. For detailed results about the estimation of doses used, see Table S1.

\section{Statistical analysis}

To test for differences in stimulant use in the investigated locations, Kruskal-Wallis one-way analysis of variance and Nemenyi test (Nemenyi, 1963) were used. Differences between years and the presence of monotonic trends were tested using pairwise Students $t$-test and Mann-Kendall test, respectively. All calculations and statistical tests were performed using $R$ software (R Core Team, 2013) and $p$-values $<0.05$ were regarded as statistically significant.

\section{Results and discussion}

Geographical differences in the stimulant use

Proportions of stimulants used were computed as described in the data analysis section. This allowed to investigate geographical differences in the types of stimulants used (Figure 2). An interesting relationship was observed between the relative abundance of cocaine use and the size of the investigated population. In fact, cocaine was the most predominant substance in the cities of Antwerp and Brussels (i.e., 50-75\% of total number of stimulant doses), while the relative contribution of cocaine to the overall stimulant use was clearly lower in smaller cities. On the contrary, these smaller cities were characterised by a more widespread use of amphetamine compared to the larger catchments (Figure 2). Thus, the findings suggest that the pattern of stimulant use and/or the availability of cocaine and amphetamine are related to the catchment size and, potentially, to the degree of urbanisation (i.e., amphetamine being more common in less urbanised and more isolated areas). The only exception is Ostend, which shows a consumption 
pattern similar to the one found in smaller cities, while the size of the served population is approximately 160,000 inhabitants. The characteristics of this catchment could be an explanation for this observation. In fact, the WWTP serves the city of Ostend itself (70,000 inhabitants) but also surrounding smaller cities and villages (total catchment population 160,000 inhabitants) and is located on the seaside and distant from other major urban centres. Thus, it could still be considered as a less urbanised area, compared to genuine urban centres such Brussels and Antwerp. The distinction between locations where cocaine or amphetamine use was more prevalent could also be statistically confirmed. Brussels and Antwerp could be grouped together (large cities), while the remaining catchments (smaller cities) formed a second group (Nemenyi-tests, $\alpha=0.05$ ). Regarding methamphetamine, its prevalence in the cities of Brussels and Antwerp appeared similar $(p=$ $0.1383)$, while its consumption was lower elsewhere. Nonetheless, methamphetamine use was generally very limited in the investigated locations and represented only a small fraction of the total amount of stimulants used (i.e. 0-3\%). In the case of MDMA, no particular difference between catchments could be highlighted. Interestingly, highly urbanised areas and large cities (i.e. Brussels and Antwerp), where a higher consumption of MDMA could have been expected, were generally not different from catchments comprising smaller cities and villages $(p>0.05)$. Globally, the results indicate that cocaine and amphetamine are the predominant stimulants used in the investigated areas. However, their occurrence seems to be inversely related, with cocaine being predominant in large urban areas, while amphetamine is more widespread in less urbanised areas.

\section{Temporal trends in the stimulant consumption}

Annual variations

As the use of the four stimulants in some of the investigated locations has been studied for multiple years (2011-2015), annual changes in the pattern of stimulant use could be assessed for Antwerp, Brussels and Ninove (Figure 3). The total number of stimulant doses used in Antwerp between 2012 and 2014 was below the four-year average by $12 \%$ and $6 \%$, respectively, whereas the use in 2013 and 2015 was above the average consumption by about $10 \%$. There was no significant variation in cocaine consumption in Antwerp over four years. In contrast, a steadily increasing trend in amphetamine consumption was observed. Its use was significantly higher in 2014 and 2015 compared to 2012 (pairwise $t$-test, $p<0.05$ ). Although the use of methamphetamine was generally low, a continuous rising trend in its consumption was noticed over the monitoring period. MDMA consumption was not significantly different among years. Cocaine was the most prevalent stimulant in Antwerp, and accounted for about $50-60 \%$ of the total stimulant use over the four years. Amphetamine ranked as the second most used stimulant, making up $30-37 \%$ of the total stimulant 
use in Antwerp. The portion of MDMA used was substantially lower than that of cocaine and amphetamine, and constituted only $6-8 \%$ of the total stimulant use. Methamphetamine contributed to less than $2 \%$ of the total stimulant use over time. This pattern remained constant throughout the monitoring period, implying that the consumption of these stimulants in the city of Antwerp remained stable over four years. Interestingly, the pattern of drug use obtained from WBE in Antwerp was very similar compared to the self-report data from 2013 (HIS data) for the whole province of Antwerp, in which cocaine use was predominant, followed by amphetamine and/or MDMA (Figure 3 and Gisle, 2014).

In Brussels, a sharp and significant increase in stimulant use was observed between the period 2011-2013 and 2015 (pairwise $t$-test, $p<0.05$ ). Cocaine was predominant in the metropole of Brussels, and contributed to $64-74 \%$ of the total stimulant use. Amphetamine was the second most popular stimulant and accounted for $16-27 \%$ of the total amount of stimulants used. Compared to cocaine and amphetamine, MDMA (5-9\%) and methamphetamine (about $1 \%$ ) consumption constituted small to negligible proportions of the total. The pattern of stimulant use in 2011 and 2012 appeared slightly different from that in 2013 and 2015. The latter two years had a greater share of cocaine use, which reduced the proportion of amphetamine use by about two times. The usage pattern in this large city slightly varied over the monitoring period, suggesting a modest change in the pattern of stimulant use in the catchment. The picture drawn from WBE (cocaine vs. amphetamine: $75 \%$ vs. $25 \%$ of the total use) was different from the HIS data ( $51 \%$ vs. $49 \%$ of the total 12-months prevalence in 2013) in this city (Gisle, 2014). This suggests that a large proportion of cocaine use is being underreported in the Brussels-Capital region. This could be due to the difficulties in reaching (a) people living outside the capital who access the area only on daily basis (e.g. commuters) or for short/temporal employments (e.g. businessmen, politicians) as well as (b) heavy and marginalised cocaine users who do not have a fixed residence.

In Ninove, the total stimulant use was stable along the years (pairwise $t$-test, $p>0.05$ ). Methamphetamine consumption was negligible in the studied catchment. Amphetamine was the most prevalent substance in this small city, where it accounted for $64-67 \%$ of the total stimulant use. Cocaine was the second most popular stimulant, making up $27-30 \%$ of the total stimulant use. Compared to cocaine and amphetamine, the MDMA consumption constituted for about $5-7 \%$ of the total stimulant use. The usage pattern in Ninove remained stable over three years, implying constant consumption in this area. Also, the pattern obtained in this study strongly matched with the prevalence data from 2013 for the province of East-Flanders (Gisle, 2014), further supporting the outlined structure of stimulant use in the studied catchment. Similar results were observed also in 
the nearby small city of Geraadsbergen, where amphetamine consumption was predominant followed by cocaine and MDMA (Fig. S1).

\section{Weekly variations}

In order to assess the weekly pattern of stimulants use, the percentage of doses consumed each day relative to the total weekly consumption was calculated (Figure 4). In Antwerp, Brussels and Ninove, the three highly prevalent stimulants showed lower use in the middle of the week, followed by an increase towards the weekend. For cocaine and amphetamine, approximately $12-$ $14 \%$ usage was observed during the weekday while about $16-20 \%$ usage was observed during the weekend in the three studied areas. This weekend change in cocaine and amphetamine use was less obvious than that in MDMA in the three cities. In Antwerp and Ninove, 20\% MDMA use was observed in the weekend which was about twice as high compared to weekdays. Such difference in MDMA use between weekday and weekend was even more pronounced in Brussels (five times higher). These results illustrate that, with regards to the overall weekly consumption, the pattern of MDMA use is clearly more intense on the weekends, likely because of its more pronounced recreational connotation, compared to cocaine and amphetamine whose consumption is also strongly influenced by regular users. The higher use of MDMA during the weekend is also reflected slightly increased loads measured on Mondays, which are likely due to the residual excretion of the weekend consumption and the particular pharmacokinetics of MDMA (i.e., non-linear elimination rate (De La Torre et al., 2000). Yet, whether the increase in MDMA use is due to a change in preferences among users who consume cocaine or amphetamine during the week, the contribution of recreational users consuming only MDMA during the weekend, or a mixture of both scenarios, cannot be answered through WBE.

\section{Conclusions}

This study applied WBE to detect spatiotemporal changes in the relative amounts of stimulants used in Belgium. Although precisely estimating consumption in terms of doses remains delicate, due to the uncertainties linked to back-calculating amounts used and the variability in doses taken, this approach allows drawing a rough image about preferences of stimulant use in Belgium. The results show that in larger cities, there is a preference for cocaine as stimulant while in smaller cities amphetamine is the stimulant of choice. The fraction of MDMA used compared to amphetamine and cocaine is much lower. Methamphetamine use has a marginal share in Belgium's stimulant market. Overall, no significant changes could be observed in the relative amounts of stimulants used in the period 2011-2015, suggesting that the consumption habits for the 
investigated substances remained stable over these years. Investigation of the weekly patterns of stimulant use revealed a more pronounced increase in MDMA use on the weekends compared to cocaine and amphetamine.

\section{Acknowledgements}

We would like to thank the staff at Toxicological Center (University of Antwerp), Philanthropic Educational Organization (PEO) and American Association of University Women (AAUW) for their support. Financial support: Juliet Kinyua acknowledges the EU International Training Network SEWPROF (Marie Curie- Grant number 317205) for her doctoral fellowship. Dr. Alexander van Nuijs, Dr. Foon Yin Lai, and Dr. Frederic Been acknowledge the Flanders Foundation for Research (FWO), the University of Antwerp and the Swiss National Science Foundation (SNF, P2LAP2_164892) for their post-doctoral fellowships, respectively.

\section{References}

Been F, Bijlsma L, Benaglia L, Berset J-D, Botero-Coy AM, Castiglioni S, Kraus L, Zobel F, Schaub MP, Bücheli A, Hernández F, Delémont O, Esseiva P, Ort C. Assessing geographical differences in illicit drug consumption - A comparison of results from epidemiological and wastewater data in Germany and Switzerland. Drug Alcohol Depend 2016;161:189-99.

Been F., Benaglia L., Lucia S., Gervasoni J-P., Delémont O., Esseiva P. Data triangulation in the context of opioids monitoring via wastewater analyses, Drug Alcohol Depend 2015; 151:203-10

Castiglioni S, Bijlsma L, Covaci A, Emke E, Hernandez F, Reid M, Ort C, Thomas KV, van Nuijs ALN, de Voogt P, Zuccato E. Evaluation of Uncertainties Associated with the Determination of Community Drug Use through the Measurement of Sewage Drug Biomarkers. Environ Sci Technol 2013;47:1452-60

Castiglioni S, Thomas KV, Kasprzyk-Hordern B, Vandam L, Griffiths P. Testing wastewater to detect illicit drugs: State of the art, potential and research needs. Sci Total Environ 2014;487:613-20.

Caulkins JP. The need for dynamic drug policy. Addiction 2007;102:4-7

De La Torre, R., M. Farré, J. Ortuño, M. Mas, R. Brenneisen, P. N. Roset, J. Segura, and J. Cami. “NonLinear Pharmacokinetics of MDMA ('ecstasy') in Humans." British Journal of Clinical Pharmacology 49 (2000): 104-9.

European Monitoring Centre for Drug and Drug Addiction (EMCDDA). The EU drugs strategy (201320) and its action plan (2013-16). Available at http://www.emcdda.europa.eu/topics/pods/eudrugs-strategy-2013-20. 
European Monitoring Centre for Drug and Drug Addiction (EMCDDA). European Drug Report 2015. Publications Office of the European Union, Luxembourg, 2015.

European Monitoring Centre for Drugs and Drug Addiction (EMCDDA). Drug profiles. Available at: http://www.emcdda.europa.eu/drug-profiles (accessed 2.29.16).

Gisle L. Illicit drugs use. In: Gisle L, Demarest S (ed.). Health Interview Survey 2013. Report 2: Health Determinants \& Lifestyle. WIV-ISP, Brussels, 2014 (in Dutch).

Jones HE, Hickman M, Kasprzyk-Hordern B, Welton NJ, Baker DR, Ades AE. Illicit and pharmaceutical drug consumption estimated via wastewater analysis. Part B: Placing back-calculations in a formal statistical framework. Sci Total Environ 2014;487:642-50.

Khan U, Nicell JA. Sewer epidemiology mass balances for assessing the illicit use of methamphetamine, amphetamine and tetrahydrocannabinol. Sci Total Environ 2012;421422:144-62.

Khan U, Nicell JA. Refined sewer epidemiology mass balances and their application to heroin, cocaine and ecstasy. Environ Int 2011;37:1236-52.

Muggah R, Aguirre K, Szabo de Carvalho I. Measurement Matters: Designing New Metrics for a Drug Policy That Works. Igarapé Publication. Instituto Igarapé, 2015.

Nemenyi PB. Distribution-free Multiple Comparisons. Princeton University, 1963.

Ort C, Lawrence MG, Reungoat J, Müller JF. Sampling for PPCPs in Wastewater Systems: Comparison of Different Sampling Modes and Optimization Strategies. Environ Sci Technol 2010;44:6289-96.

R Core Team. R: A language and environment for statistical computing. R Foundation for Statistical Computing, Vienna, Austria, 2013.

Ritter A. Studying illicit drug markets: Disciplinary contributions. Int J Drug Policy 2006;17:453-63.

van Nuijs ALN, Tarcomnicu I, Jorens PG, Bervoets L, Blust R, Neels H, Covaci A. Analysis of drugs of abuse in wastewater by hydrophilic interaction liquid chromatography-tandem mass spectrometry. Anal Bioanal Chem 2009;395:819-28.

Zuccato E, Chiabrando C, Castiglioni S, Bagnati R, Fanelli R. Estimating community drug abuse by wastewater analysis. Environ Health Persp 2008;116:1027-32. 
Table 1: Sampled wastewater treatment plants (WWTP), main area and population served, and sampling details.

\begin{tabular}{|c|c|c|c|c|c|}
\hline $\begin{array}{l}\text { Name used in } \\
\text { this study }\end{array}$ & WWTP & $\begin{array}{l}\text { Area served by } \\
\text { WWTP }\end{array}$ & $\begin{array}{c}\text { Population } \\
\text { served (census } \\
\text { data) }\end{array}$ & $\begin{array}{l}\text { Sampling } \\
\text { mode }\end{array}$ & Sampling dates \\
\hline Antwerp* & $\begin{array}{l}\text { Antwerpen- } \\
\text { Zuid }\end{array}$ & $\begin{array}{l}\text { Antwerp (city } \\
\text { centre) }\end{array}$ & 130,200 & $\begin{array}{c}\text { Time- } \\
\text { proportional }^{\circ}\end{array}$ & $\begin{array}{c}09 / 02 / 2011-15 / 03 / 2011 \\
17 / 04 / 2012-23 / 04 / 2012 \\
06 / 03 / 2013-12 / 03 / 2013 \\
04 / 04 / 2014-10 / 04 / 2015 \\
18 / 03 / 2015-24 / 03 / 2015\end{array}$ \\
\hline Antwerp* & Deurne & Antwerp (suburbs) & 213,900 & $\begin{array}{c}\text { Time- } \\
\text { proportional }^{\circ}\end{array}$ & $\begin{array}{c}17 / 04 / 2012-23 / 04 / 2012 \\
06 / 03 / 2013-12 / 03 / 2013 \\
04 / 04 / 2014-10 / 04 / 2014 \\
18 / 03 / 2015-24 / 03 / 2015\end{array}$ \\
\hline Brussels & Brussel-Noord & $\begin{array}{c}\text { Brussels-Capital } \\
\text { region }\end{array}$ & 954,000 & $\begin{array}{l}\text { Volume- } \\
\text { proportional\$ }\end{array}$ & $\begin{array}{c}09 / 03 / 2011-15 / 03 / 2011 \\
17 / 04 / 2012-23 / 04 / 2012 \\
06 / 03 / 2013-12 / 03 / 2013 \\
18 / 03 / 2015-25 / 03 / 2015\end{array}$ \\
\hline Geraardsbergen & Geraardsbergen & Geraardsbergen & 29,000 & $\begin{array}{c}\text { Time- } \\
\text { proportional }^{\circ}\end{array}$ & $\begin{array}{l}19 / 03 / 2014-25 / 03 / 2014 \\
11 / 03 / 2015-17 / 03 / 2015\end{array}$ \\
\hline Lier & Lier & Lier & 31,500 & $\begin{array}{c}\text { Time- } \\
\text { proportional }^{\circ}\end{array}$ & $26 / 11 / 2014-02 / 12 / 2014$ \\
\hline Ninove & Ninove & Ninove & 36,200 & $\begin{array}{c}\text { Time- } \\
\text { proportional }^{\circ}\end{array}$ & $\begin{array}{l}06 / 03 / 2013-12 / 03 / 2013 \\
19 / 03 / 2014-25 / 03 / 2015 \\
11 / 03 / 2015-17 / 03 / 2015\end{array}$ \\
\hline Ostend & Oostende & $\begin{array}{l}\text { Ostend and } \\
\text { surrounding villages }\end{array}$ & 160,000 & $\begin{array}{c}\text { Time- } \\
\text { proportional }^{\circ}\end{array}$ & 23/04/2015-29/04/2015 \\
\hline Koksijde & Wulpen & $\begin{array}{c}\text { Koksijde and } \\
\text { surrounding villages }\end{array}$ & 78,400 & $\begin{array}{c}\text { Time- } \\
\text { proportional }^{\circ}\end{array}$ & $\begin{array}{l}21 / 03 / 2013-27 / 03 / 2013 \\
11 / 03 / 2015-17 / 03 / 2015\end{array}$ \\
\hline
\end{tabular}

${ }^{*}=$ data from WWTPs combined to obtain data for whole of Antwerp; ${ }^{\circ}=$ sampling intervals of 10 minutes; ${ }^{\$}=$ sampling intervals of $1000 \mathrm{~m}^{3}$. 
Table 2: Parameters used to estimate the number of doses used and to assess the uncertainty in the estimates. In their study, Khan \& Nicell $(2012,2011)$ reported a list of relevant pharmacokinetic studies, and the corresponding excretion rates, for cocaine, amphetamine, methamphetamine and MDMA. The reported excretion rates were weighted by the inverse of the variance and used to calculate the global mean $(\mu)$ and standard error (SE) for each substance.

\begin{tabular}{|c|c|c|c|c|}
\hline & & Distribution & \multicolumn{2}{|r|}{ Values } \\
\hline \multicolumn{2}{|r|}{ Flow } & $\begin{array}{l}\text { Normal } \\
\left(\mu, \mathrm{SE}^{2}\right)\end{array}$ & $\begin{array}{r}\mu \text { : Daily } f \\
\text { SE: An error of } \\
\text { th }\end{array}$ & $\begin{array}{l}\text { easured by the WWTP }\left[\mathrm{m}^{3} / \text { day]. }\right. \\
\text { \% was considered for the estimation of } \\
\text { flow (Been et al., 2016). }\end{array}$ \\
\hline \multicolumn{2}{|c|}{ Concentration } & $\begin{array}{l}\text { Normal } \\
\left(\mu, \mathrm{SE}^{2}\right)\end{array}$ & \multicolumn{2}{|c|}{$\begin{array}{l}\mu \text { : Measured analyte concentration [ng/L]. } \\
\text { SE: Uncertainty of analysis of drug residues in wastewater } \\
\text { was set to } \pm 25 \% \text { (Been et al., 2016). }\end{array}$} \\
\hline \multirow{4}{*}{ Excretion } & $\begin{array}{c}\text { Cocaine } \\
\text { (Benzoylecgonine) }\end{array}$ & Beta $(\alpha, \beta)$ & $\begin{array}{l}\mu: 30.6 \% \\
\text { SE: } 3.4 \%\end{array}$ & \multirow{4}{*}{$\begin{array}{l}\mu \text { and SE were calculated as the } \\
\text { inverse variance weighted average of } \\
\text { data reported in the review by Khan } \\
\text { and Nicell }(2012,2011) .\end{array}$} \\
\hline & Amphetamine & Beta $(\alpha, \beta)$ & $\begin{array}{l}\mu: 15.8 \% \\
\text { SE: } 1.8 \%\end{array}$ & \\
\hline & Methamphetamine & Beta $(\alpha, \beta)$ & $\begin{array}{l}\mu: 29.1 \% \\
\text { SE: } 0.9 \%\end{array}$ & \\
\hline & MDMA & Beta $(\alpha, \beta)$ & $\begin{array}{l}\mu: 28.6 \% \\
S E: 2.6 \%\end{array}$ & \\
\hline \multirow{4}{*}{ Doses } & Cocaine & $\begin{array}{l}\text { Normal } \\
\left(\mu, \mathrm{SE}^{2}\right)\end{array}$ & $\mu: 100 \mathrm{mg}$ & \multirow{4}{*}{$\begin{array}{l}\text { Doses were derived from figures } \\
\text { reported by the EMCDDA (European } \\
\text { Monitoring Centre for Drugs and } \\
\text { Drug Addiction, 2016). } \\
\text { The uncertainty (SE) on the doses } \\
\text { was fixed to } \pm 25 \% \text {. }\end{array}$} \\
\hline & Amphetamine & $\begin{array}{l}\text { Normal } \\
\left(\mu, \mathrm{SE}^{2}\right)\end{array}$ & $\mu: 50 \mathrm{mg}$ & \\
\hline & Methamphetamine & $\begin{array}{l}\text { Normal } \\
\left(\mu, \mathrm{SE}^{2}\right)\end{array}$ & $\mu: 50 \mathrm{mg}$ & \\
\hline & MDMA & $\begin{array}{l}\text { Normal } \\
\left(\mu, \mathrm{SE}^{2}\right)\end{array}$ & $\mu: 100 \mathrm{mg}$ & \\
\hline
\end{tabular}




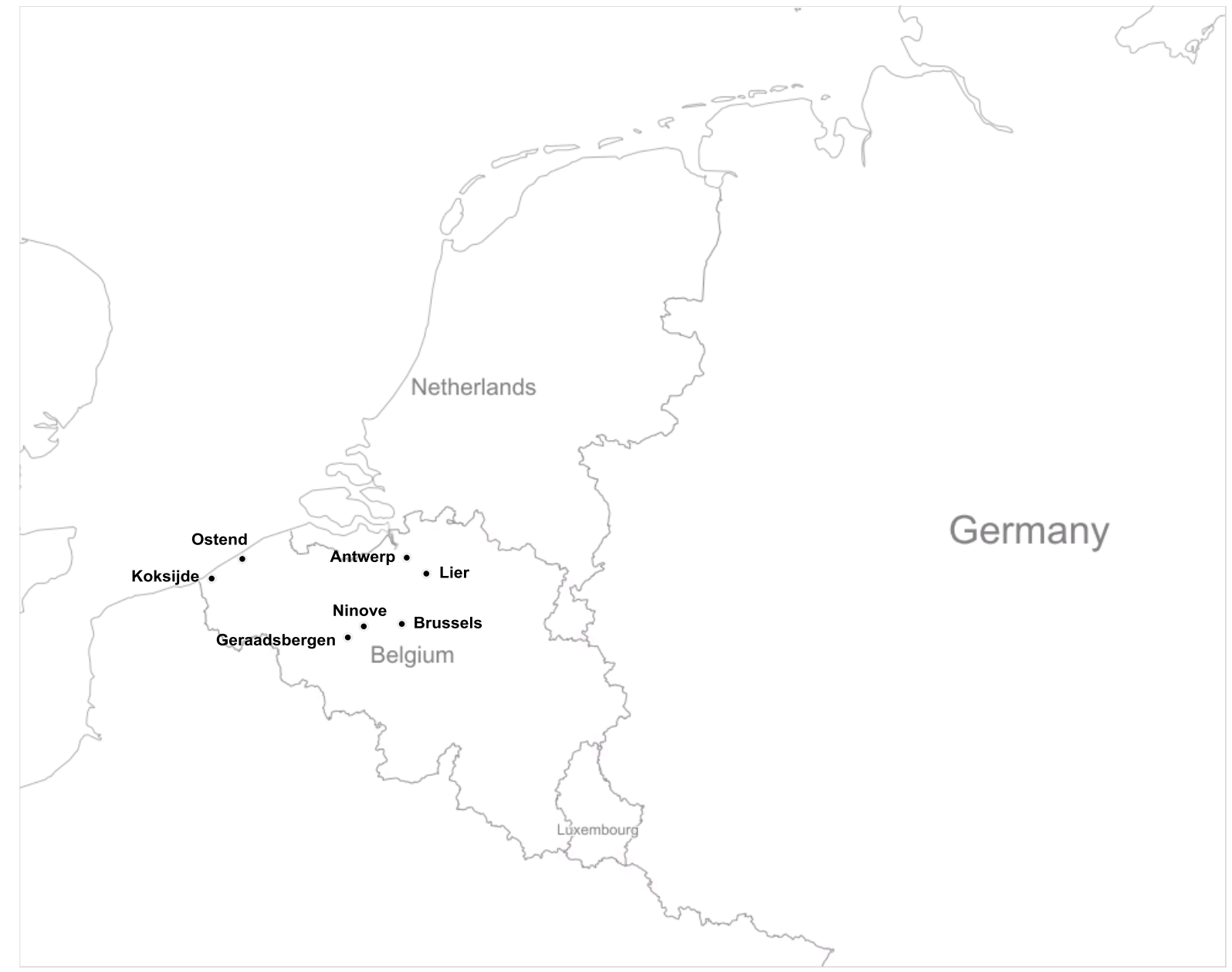

Figure 1. Map of Belgium with sampling locations 

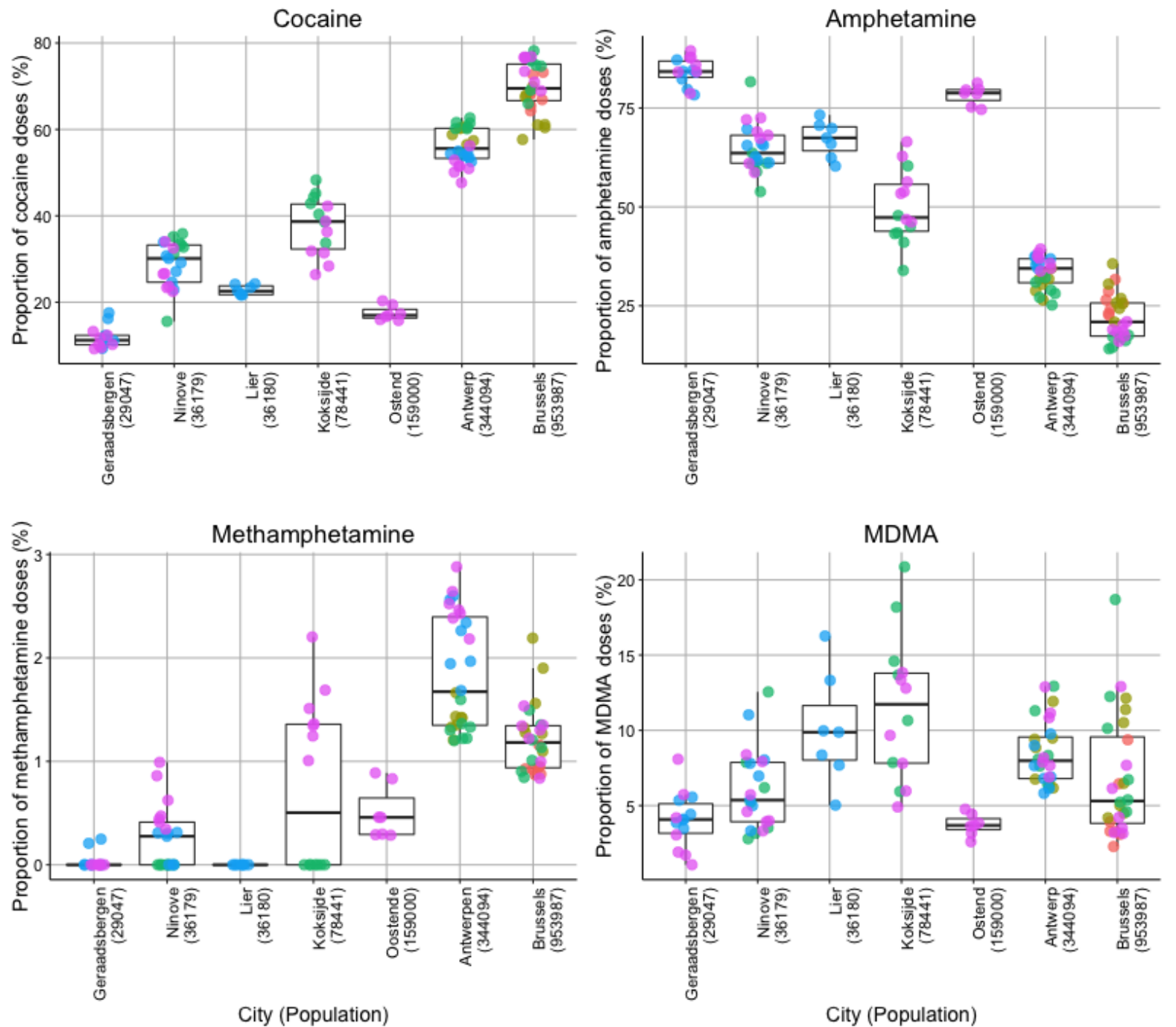

- 2011 • 2012 • 2013 • 2014 • 2015

Figure 2: Distribution and typology of stimulants used in Belgian cities between 2011 and 2015 

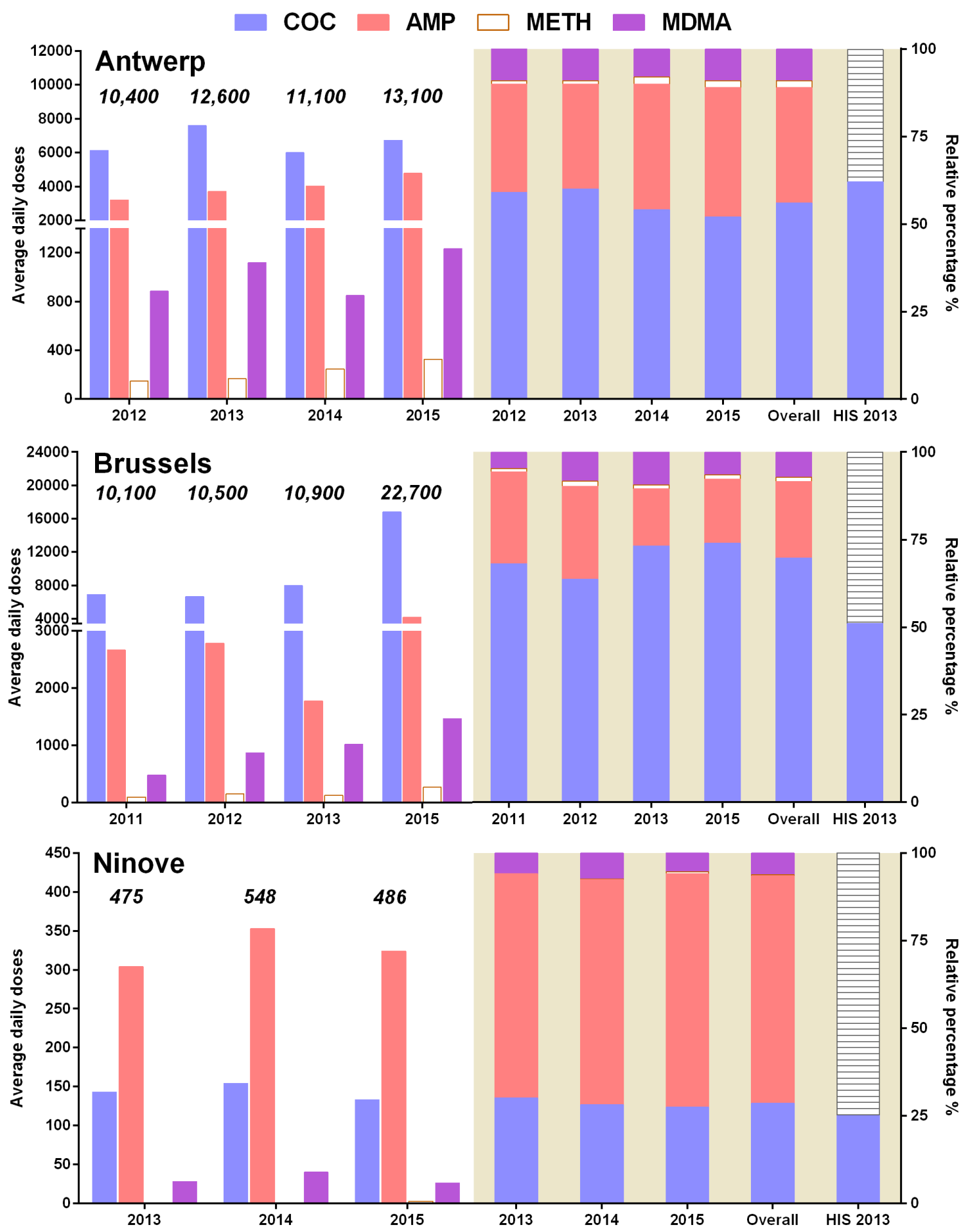

Figure 3: Temporal patterns of stimulant use in Antwerp, Brussels and Ninove. Left in white background: absolute average doses of each stimulant over years. The numbers represent the combined total of the doses of stimulants used. Right in grey background: relative composition profile of the stimulants per year. Overall: the average relative composition profile of the stimulants over the years. The HIS 2013 bar represents the relative proportion of the prevalence of cocaine (blue) or either amphetamine or ecstasy in the past 12 months for the population aged 15-64 for the province where the WWTP is located (Gisle, 2014). 

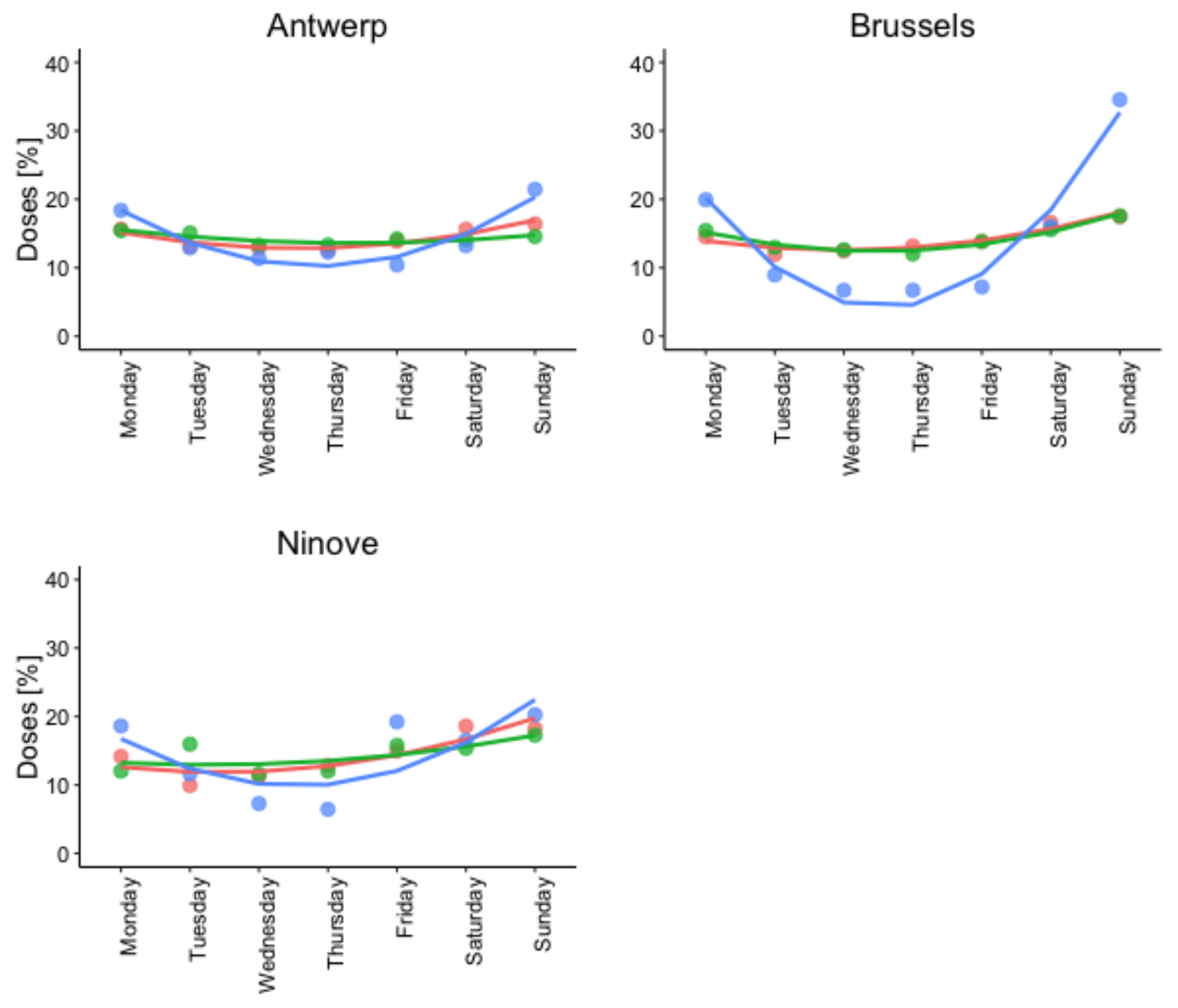

\section{Cocaine - Amphetamine - MDMA}

Figure 4: Weekly trends of cocaine, amphetamine and MDMA use in Antwerp, Brussels and Ninove. For each day, the percentage of the total number of doses consumed during the week is shown. Lines $=2^{\text {nd }}$ order polynomial trend line. 

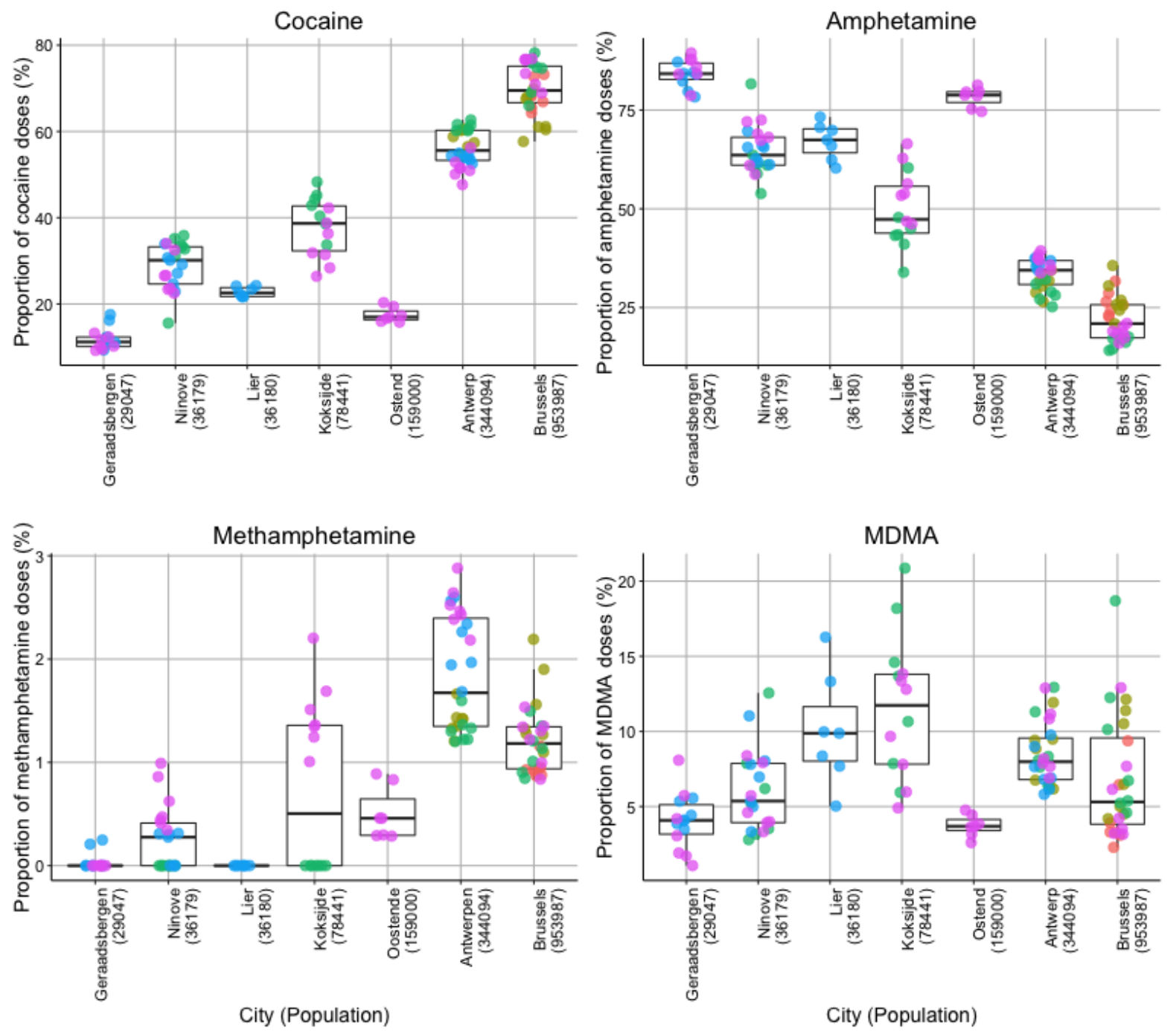

- 2011 - 2012 - 2013 • 2014 - 2015 